\title{
The Effect of Functional Resistance Drills Using Elastic Band On Some of Physical and Kinematic Variables On Release Phase in Javelin Throw Event.
}

\section{Mohammed Aldiasty Awad}

Sports Training Department, Faculty of Physical Education, Mansoura University, Egypt.

\begin{abstract}
The purpose of this study is to identify the effect of functional resistance drills using elastic band on some of physical and kinematic variables on release phase in javelin throw event. Experimental approach was used with one experimental group sample was intentionally selected form under 20 years javelin thrower at Mansoura Sports Stadium and consisted 6 javelin thrower. the researcher used the experimental method and the research sample was selected from intentional second-year males students of the Faculty of Physical Education - Mansoura University which have level apical featured in the competition javelin and the number (20) students were divided into two equal groups functional resistance drills program applied in special preparation phase for 10 weeks 4 trainings unites a week with repetitions from 8 to 12 in 3 sets to 5. Conclusions functional resistance training drills using elastic band has positive effect on improving the maximum strength, power of two legs and motor balance to the study sample. Functional resistance training using elastic band led to improved height, angle, speed release and throwing distance of the study sample in the javelin event.
\end{abstract}

Key word: functional resistance drills - elastic band - kinematic variables - javelin throw release phase ..

\section{Introduction:}

$\mathrm{R}$ eaching out to achieve the best digital achievements in javelin throw event, that require access to technical performance as close to optimal by linking the speed of approach and put throwing in order to enable the contestant to give the javelin best speed launch during the release stage, through modern techniques and variety of training methods in addition to the development of assistive equipment's for practical training.

The researcher believe the release phase are the great importance of being a turning point between what it acquired through the contestant approaching the speed of horizontal transfer stage, trying to release of javelin through the stage, according to the kinematic variables the special nature of the movement during this phase.

By the end of steps approaching preparing the contestant is preparing to throwing and release phase and this is Khaled Wahed Ebrahim (2014), quoting Zaki Darwish and Adel Abdalhafez (1994) referred to that after landing his left foot forward, pushing the right earth guy strongly in the direction of throwing and thus pushing the pelvis of spins strongly forward and up the trunk after that the maximum curvature of the back like a character (C), and preceded likely movement of the left arm, which works to lengthen the chest muscles reverse chucking must delay entry aimed at throwing process arm as less muscle (the limbs) strength until the muscles of legs and torso ends to make the maximum her attraction forward. (11) the arrival of the contestant to put curvature stretched (C) is attached above the grip and make the humerus with forearm angle of (90 degrees) to enact a javelin up toward chucking and that any defect performance of the thrower to this situation will reflect negatively on kinematics affecting distance variables throwing that is Tom (2001) Refers. (18)

Therefore throwing distance affected by kinematics variables on release phase This is what was agreed upon all of Chiu (2009 m) with Murakami, m et al (2006) and represented those variables on the rise above the point of release, the speed of the release, angle release, angle attack tool to Besides wind speed. (1) (15)

While the throwing distance in the javelin rely on the values of kinematic variables release besides affecting it forces during flight, and release angle is the angle between the outcome of the spead of the weight of the javelin and the center line of horizontal passing the weight of the Javelin center path at the moment of its launch and this is referred to all of Viitasalo adds, Mononen and Norvapalo (2003). (13)

So release angle is the important factors that contribute to the length of the flight javelin distance angle in addition to that there is the extent of the amount of release angle depends on the speed of first Instance for the start of the Javelin and strength of the Javelin "throwing force" and the direction of the wind and the optimal angle javelin throw in javelin competition, according to some sport models and rules of javelin throwing is 35 degrees and this is referred to all of Maryniak, Kozdraś and Golińska (2009). (6) 
The researcher believes the importance of the relationship between the physical demands and motor duties for this stage because of their importance and impact on the throwing distance, which it help muscle strength of various kinds on the implementation of the duties and motor which in turn affects motor spead development and therefore the foundation to reach the high levels.

Performance analysis and to identify defects or features of the technique used by the athlete is considered one of the factors that can help the coach to designate or identify the type of training needs and commensurate with the athlete to improve his performance and it may be a drawback in lack of physical or described in the player's own performance technique and this was confirmed by Mohamed Brekaa and Kharya Elsokary (2002). (14)

During the past few years has become a functional strength training commonly used in the sports field of in addition to being used under several names, such as integrated training and model training was confirmed by Christine Cunningham, (2000). (2)

During the traditional programs is increased muscle strength for a muscle without training similar movements for the technical performance, while functional drills include several muscle groups and joints for both parties, "top and bottom" as well being used alternative options within training assistance ways to improve the technical performance compared to traditional drills, and it fits with all ages and contribute to the improvement of all physical abilities, where they increase and enhance the muscles strength endurance, motor balance, agility, where lead full motor joints term and This is indicated by Tiana, W., et, al (2010). (17)

And the difference between specific and functional drills Christine Cunningham (2000) refers to be functional training drills performed on the movements of the specific drills is typically the private nature of the performance muscles, plus it is a key part of the functional training basics. (2)

knowing a combination of strength training and balance lead in the same time, it is also an integrated and multilevel movements (front, transverse and sagittal) include acceleration, stability and deceleration, in order to improve motor ability, the central strength (the spine and the middle of the body) and neuromuscular efficiency and this is Fabio Comana (2004)refered. (6)

explaining the importance of functional strength training drills all training programs should include functional strength drills, during they perform the competition; we find that the weight of the body center is a movable and ever-changing, especially in activities that require forward and backward movements and this is Scott Gaines, (2003) refered. (10).
Functional training programs consist of drills Central stability Core stability which movements performed a few repetitions and severity of the medium with the gradual progress in performance in order to achieve stability and self-control neuromuscular, central power Core Strength a related dynamic uses movements external resistors in all kinetic levels and aims to achieve muscle strength and motor integration, the core power movements and are therefore characterized by the production of power and this is Michael, B., (2004) confirmed. (13)

Functional training has the characteristics and attributes of the most important to focus on the muscles of the middle group, multiple levels, multiple joints, control of the antibalance, one limb, and the parties alternating, integrative movement, specific activity, the quality of speed and this is Dave Schmitz (2003) referred. (3)

the resistance drills using elastic band has a special in many strength training programs stature because of their effective impact on the technical performance and possible performance and integrated in the drills along the extent of the sports movement in order to reform and improve many of the sports movements and this is Wallace, BJ., Et, al (2006) confirmed. (20)

It is already clear the importance of functional resistance training using elastic bands in linking the physical demands and duties kinetic thereby contributing to improving the level of performance compared to traditional drills where the muscle power of various kinds to help implement the duties motor which in turn affects motor speed and employment development to achieve high levels of digital achievement.

And include duties kinetic take the thrower to put the right throwing position before release of the Javelin, which provides access to the largest amount of power and a longer path to the acceleration Javelin and give the angle of the release and the spead of the release " Kinematics" influencing variables in the release phase," and that the acquisition and mastery of performance by release back to its automated stage in performance requires avoiding excessive movements and errors in this important stage.

Through Reference Survey studies and related researches (1) (2) (3) (4) (5) (7) (8)(12)(13) (15) (19) have been identified the appropriate kinematic measurements kown competition variables throw following javelin, and the survey conducted by the researcher to study the performance by release phase the (5) students of the third year phase - specialty training track and field competitions - Faculty of Physical Education - Mansoura University and they have already learned the competition javelin which have level digital featured in the contest and registered Dakahlia Athletics area through the performance of the best attempts analysis turns out a reduction in the values of 
certain variables Kinematics to release ranging height release to have between $182 \mathrm{~cm}: 194 \mathrm{~cm}$ and spead release between $12.5 \mathrm{~m} / \mathrm{s}$ to $14.6 \mathrm{~m} / \mathrm{s}$ as it was release $22: 26$ angle while the value of the ideal release of 35-degree angle, according to the referred Maryniak, J, Kozdraś, E , Golińska,E (2009) study .(12)

So the researcher is trying through this experimental study was to investigate the effect of functional resistance drills using elastic band on some of the physical and Kinematic variables to release stage in the javelin throw event. Research procedures :

Experimental approach was used with one experimental, control group and pre- post measurements in Mansoura University Olympic Village and Mansoura stadium athletic hall, and track and field, pilot studies, pre and post measurements, and main study different rates weight

Table (1)

Statistical characterization of study sample in basic and physical variables (under study) $n=20$

\begin{tabular}{|c|c|c|c|c|c|}
\hline The variables & $\begin{array}{l}\text { Measurement } \\
\text { unit }\end{array}$ & Mean & Median & $\begin{array}{c}\text { Std. } \\
\text { Deviation }\end{array}$ & Skewness \\
\hline Age & to the nearest half-year & 19.455 & 19.500 & 0.196 & -0.083 \\
\hline Height & to the nearest $\mathrm{cm}$ & 180.700 & 182.000 & 4.169 & -0.084 \\
\hline Weight & to the nearest $\mathrm{kg}$ & 72.050 & 72.000 & 2.282 & 0.257 \\
\hline $\begin{array}{c}\text { the time of } 30 \text {-meter sprint from a } \\
\text { crouch start test }\end{array}$ & $\mathrm{S}$ & 4.018 & 3.960 & 0.141 & 0.783 \\
\hline $\begin{array}{l}\text { Measuring extension muscles } \\
\text { strength for the back }\end{array}$ & $\mathrm{kg}$ & 183.315 & 184.250 & 4.207 & -0.109 \\
\hline $\begin{array}{l}\text { measuring extension muscles } \\
\text { strength of the two legs }\end{array}$ & $\mathrm{kg}$ & 268.15 & 267.00 & 4.591 & 0.284 \\
\hline Standing broad jump Test & $\mathrm{cm}$ & 226.35 & 228.00 & 5.669 & 0.056 \\
\hline Standing vertical jump test & $\mathrm{cm}$ & 38.850 & 38.000 & 2.159 & 0.319 \\
\hline $\begin{array}{l}\text { Push shot put by hands in front of } \\
\text { the body }\end{array}$ & $\mathrm{m}$ & 10.240 & 10.260 & 0.138 & -1.163 \\
\hline $\begin{array}{l}\text { push shot put by hands behind of } \\
\text { the body }\end{array}$ & $\mathrm{m}$ & 11.282 & 11.350 & 0.179 & -0.772 \\
\hline
\end{tabular}

Table (1) show the basic and physical variables for study sample are normally distributed Table (2)

Statistical characterization of study sample in muscle strength of kinematic variables for javelin thrower

\begin{tabular}{|c|c|c|c|c|}
\hline Variables & $\begin{array}{c}\text { measurement } \\
\text { unit }\end{array}$ & Mean & Median & $\begin{array}{c}\text { Skewness } \\
\text { Deviation }\end{array}$ \\
\hline High point of release & $\mathrm{Cm}$ & 187.85 & 188.00 & 1.565 \\
\hline the spead of the release & $\mathrm{m} / \mathrm{s}$ & 13.775 & 13.600 & 0.397 \\
\hline release angle & Degree & 26.805 & 26.800 & 0.763 \\
\hline throwing distance & $\mathrm{M}$ & 37.616 & 37.890 & -0.547 \\
\hline
\end{tabular}

Table (2) show the values of kinematic variables for javelin thrower in release phase for study sample are normally distributed drills has been conducted during the special preparation period within javelin thrower training program, in the period from September 28 th till December 11th, 2013 sample was intentionally selected form under (20) years javelin thrower at Mansoura Sports Stadium and consisted Kinetic analysis done using PC and video point program where (6) attempts filmed for each javelin thrower, imaging field includes release phase beginning and ending with registration of throwers numbers, according to the order of their performance and identify successful and failed attempts and then selecting best successful attempts for each thrower in research sample and then these attempts used as inputs to the computer software to start the process of kinetic analysis and to define kinematic ariables for release phase. 
Table (3)

Valence to experimental and control groups in pre - measurements of the variables under study

n $1=$ n $2=10$

\begin{tabular}{|c|c|c|c|c|c|c|}
\hline \multirow{2}{*}{ The variables } & \multirow{2}{*}{$\begin{array}{c}\text { The unit of } \\
\text { measurement }\end{array}$} & \multicolumn{2}{|c|}{ Control group } & \multicolumn{2}{|c|}{ Experimental group } \\
\cline { 5 - 7 } & Mean & $\begin{array}{c}\text { Std. } \\
\text { Deviation }\end{array}$ & Mean & $\begin{array}{c}\text { Std } \\
\text {. Deviation }\end{array}$ \\
\hline Age & $\begin{array}{c}\text { to the nearest half- } \\
\text { year }\end{array}$ & 19.480 & 0.210 & 19.430 & 0.189 & 0.560 \\
\hline Height & to the nearest cm & 182.00 & 4.110 & 179.40 & 4.006 & 1.433 \\
\hline Weight & to the nearest kg & 71.400 & 2.221 & 72.700 & 2.263 & 1.296 \\
\hline the time of 30-meter sprint from a crouch start test & $\mathrm{S}$ & 4.035 & 0.149 & 4.001 & 0.139 & 0.527 \\
\hline Measuring extension muscles strength for the back & $\mathrm{Kg}$ & 184.13 & 5.126 & 182.50 & 3.100 & 0.860 \\
\hline measuring extension muscles strength of the two legs & $\mathrm{Kg}$ & 268.50 & 3.408 & 267.80 & 5.712 & 0.333 \\
\hline Standing broad jump Test & $\mathrm{Cm}$ & 227.10 & 6.100 & 225.60 & 5.420 & 0.581 \\
\hline Standing vertical jump test & $\mathrm{Cm}$ & 38.700 & 2.263 & 39.000 & 2.160 & 0.303 \\
\hline Push shot put by hands in front of the body & $\mathrm{M}$ & 10.218 & 0.162 & 10.262 & 0.113 & 0.704 \\
\hline push shot put by hands behind of the body & $\mathrm{M}$ & 11.284 & 0.163 & 11.280 & 0.203 & 0.049 \\
\hline High point of release & $\mathrm{Cm}$ & 187.60 & 1.265 & 188.10 & 1.853 & 0.705 \\
\hline The spead of the release & $\mathrm{m} / \mathrm{s}$ & 13.610 & 0.218 & 13.940 & 0.474 & 1.999 \\
\hline Release angle & $\mathrm{Degree}$ & 26.760 & 0.849 & 26.850 & 0.709 & 0.257 \\
\hline Throwing distance & $\mathrm{M}$ & 38.024 & 0.779 & 37.207 & 3.396 & 0.741 \\
\hline
\end{tabular}

T. tabular value significant at of $0.05=2.101$

$\mathrm{D} *$

Table (4)

Statistical characterization of study sample in muscle strength of kinematic variables for javelin thrower

\begin{tabular}{|c|c|c|c|c|c|c|}
\hline \multirow{2}{*}{ The variables } & \multirow{2}{*}{$\begin{array}{c}\text { unit } \\
\text { measurement }\end{array}$} & \multicolumn{2}{|c|}{ Control group } & \multicolumn{3}{|c|}{ Experimental group } \\
\cline { 4 - 7 } & & Mean & Std. Deviation & \multirow{2}{*}{$\begin{array}{c}\text { Mean } \\
\text { Deviation }\end{array}$} & $\mathrm{t}$ \\
\hline High point of release & $\mathrm{Cm}$ & 187.60 & 1.265 & 188.10 & 1.853 & 0.705 \\
\hline The spead of the release & $\mathrm{m} / \mathrm{s}$ & 13.610 & 0.218 & 13.940 & 0.474 & 1.999 \\
\hline Release angle & Degree & 26.760 & 0.849 & 26.850 & 0.709 & 0.257 \\
\hline Throwing distance & $\mathrm{M}$ & 38.024 & 0.779 & 37.207 & 3.396 & 0.741 \\
\hline
\end{tabular}

T. tabular value significant at $0.05=2.101$

$\mathrm{D} *$

Shown in table (3) the lack of statistically significant differences between pre - measurements to experimental group and control group in the variables under study which shows the absence of that significance differences between the two groups before the start of the experiment.

\section{Main study:}

Conducted during special preparation period of training drills resistance using elastic band during the specific preparation from the competition's a training program the

javelin in the period from January 30th, 2014 to April 12th, 2014 for a period of (10) weeks with (4) trainings session a week with repetitions from 8 to 12 in 3 sets to 5 session time (2 hours). Attachment (1)

The calibration of elastic band in plastic private management of public

Labs textile chemistry of the department at the Ministry of Trade and Industry.

Table (5)

Account of the results of the three samples were analyzed for the calibration elastic band

\begin{tabular}{|c|c|c|c|}
\hline The variables & Red elastic band & Black elastic band & Blue elastic band \\
\hline Width & $2.8 \mathrm{~cm}$ & $2 \mathrm{~cm}$ & $1.25 \mathrm{~cm}$ \\
\hline Thickness & $4.67 \mathrm{Mm}$ & $4.75 \mathrm{Mm}$ & $4.846 \mathrm{Mm}$ \\
\hline Highest pull load "for $10 \mathrm{~cm}$ length" & $20.546 \mathrm{~kg}$ & $14.595 \mathrm{~kg}$ & $10.503 \mathrm{~kg}$ \\
\hline Stretch on "highest load length for $10 \mathrm{~cm}$ " & $\% 434.0$ & $439.0 \%$ & $420.133 \%$ \\
\hline
\end{tabular}

- Has been set specific dimension for the results of the

Post measurements: After completion of main study postthree-sample analysis for the elastic band by the measurements were conducted on April 13th, and 14th, competent laboratory are as follows:

2014AD. 
Statistical coefficients and factors: mean - standard

Deviation - median - convolution coefficient - Test $(\mathrm{T})$ percentage Change.

\section{Results and discussion:}

First present the results of pre and post measurement to control group in the physical variables under study.

Table (6)

Signify the differences between pre and post measurement of the control group in physical variables under study $\mathrm{n}=10$

\begin{tabular}{|c|c|c|c|c|c|c|c|}
\hline \multirow{2}{*}{ The variables } & \multirow{2}{*}{ 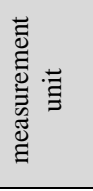 } & \multicolumn{2}{|c|}{ Pre-Measurement } & \multicolumn{2}{|c|}{ post Measurement } & \multirow{2}{*}{ 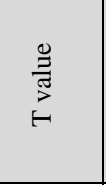 } & \multirow{2}{*}{ 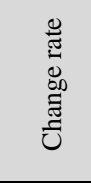 } \\
\hline & & Mean & \begin{tabular}{c|} 
Std. \\
Deviation
\end{tabular} & Mean & $\begin{array}{c}\text { Std. } \\
\text { Deviation }\end{array}$ & & \\
\hline the time of 30 meter sprint from a crouch start test & S & 4.035 & 0.149 & 4.107 & 0.940 & $0.235^{*}$ & $1.78 \%$ \\
\hline Measuring extension muscles strength for & $\mathrm{kg}$ & 184 & 5.126 & 195. & 4.745 & 10.2 & $5.96 \%$ \\
\hline the back & & .13 & & 11 & & $58 *$ & \\
\hline measuring extension muscles strength of the two legs & $\mathrm{kg}$ & 268.50 & 3.408 & 286.10 & 4.606 & $9.387 *$ & $6.55 \%$ \\
\hline Standing broad jump Test & $\mathrm{cm}$ & 227.10 & 6.100 & 238.60 & 2.413 & $8.032 *$ & $5.06 \%$ \\
\hline Standing vertical jump test & $\mathrm{cm}$ & 38.700 & 2.263 & 42.600 & 1.350 & $5.087 *$ & $10.08 \%$ \\
\hline Push shot put by hands in front of the body & M & 10.218 & 0.162 & 11.123 & 0.139 & $20.290 *$ & $8.86 \%$ \\
\hline push shot put by hands behind of the body & M & 11.284 & 0.163 & 12.473 & 0.184 & $22.212 *$ & $10.54 \%$ \\
\hline High point of release & $\mathrm{cm}$ & 187.60 & 1.265 & 195.90 & 1.853 & $22.636^{*}$ & $4.42 \%$ \\
\hline the spead of the release & $\mathrm{m} / \mathrm{s}$ & 13.610 & 0.218 & 15.850 & 0.354 & $20.044 *$ & $16.46 \%$ \\
\hline release angle & Degree & 26.760 & 0.849 & 28.250 & 0.657 & $5.001 *$ & $5.57 \%$ \\
\hline throwing distance & M & 38.024 & 0.779 & 39.925 & 0.747 & $9.200 *$ & $5.00 \%$ \\
\hline
\end{tabular}

T. tabular significant at $0.05=2.101 \mathrm{D}^{*}$

Seen from the table (4) lack of statistically significant differences between the pre- and the post measurements of the control group in the variables under study, while there

Chart (1)

change rate for variables under study for the control group

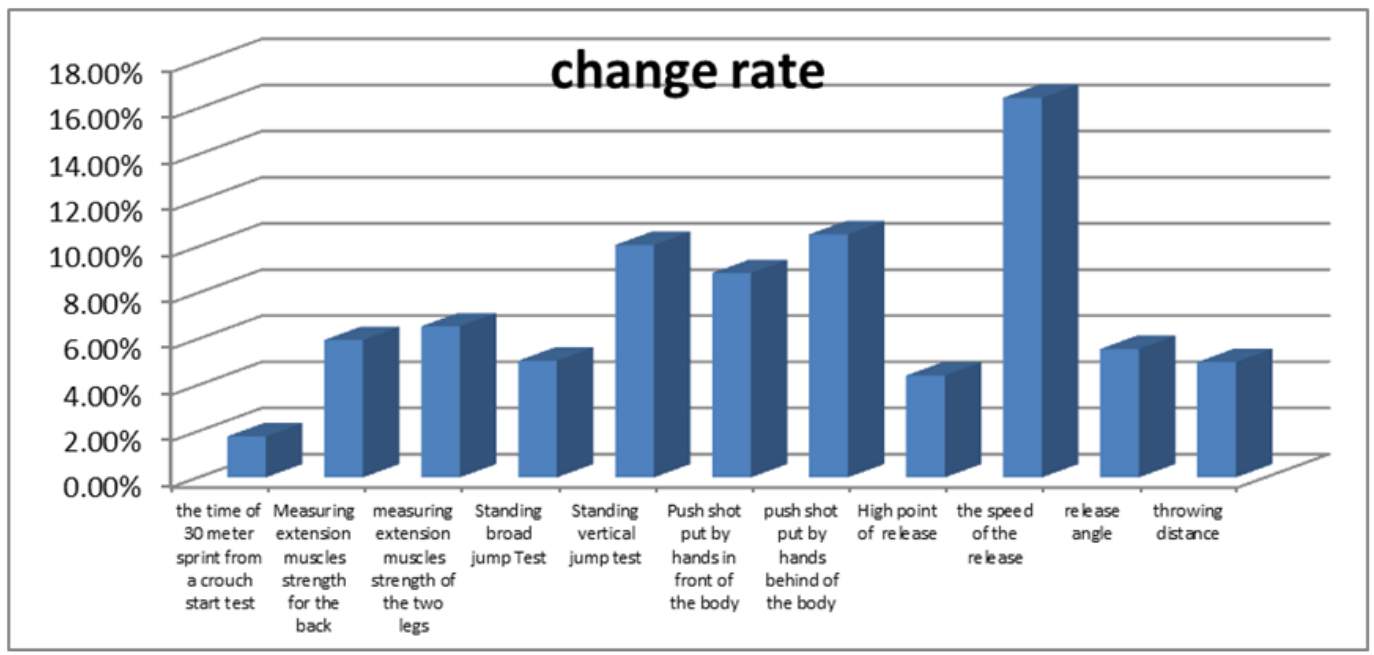

Second :Present the results of pre- and post-measurements in the variables to experimental group. 
Table (7)

Denote the differences between pre and post measurements for experimental group in variables under study $\quad \mathrm{n}=10$

\begin{tabular}{|c|c|c|c|c|c|c|c|}
\hline \multirow{2}{*}{ The variables } & \multirow{2}{*}{ 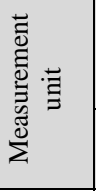 } & \multicolumn{2}{|c|}{ Pre-Measurement } & \multicolumn{2}{|c|}{ post Measurement } & \multirow{2}{*}{ t } & \multirow{2}{*}{ 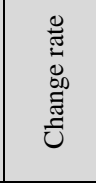 } \\
\hline & & Mean & $\begin{array}{c}\text { Std. } \\
\text { Deviation }\end{array}$ & Mean & $\begin{array}{c}\text { Std. } \\
\text { Deviation }\end{array}$ & & \\
\hline the time of 30 meter sprint from a crouch start test & $\mathrm{S}$ & 4.001 & 0.139 & 3.681 & 0.034 & 7.307 & $8.00 \%$ \\
\hline Measuring extension muscles strength for the back & $\mathrm{Kg}$ & 182.500 & 3.100 & 204.090 & 6.154 & 9.148 & $11.83 \%$ \\
\hline measuring extension muscles strength of the two legs & $\mathrm{Kg}$ & 267.800 & 5.712 & 298.100 & 6.045 & 11.274 & $11.31 \%$ \\
\hline Standing broad jump Test & $\mathrm{Cm}$ & 225.600 & 5.420 & 245.000 & 3.944 & 7.859 & $8.60 \%$ \\
\hline Standing vertical jump test & $\mathrm{Cm}$ & 39.000 & 2.160 & 45.600 & 1.955 & 7.163 & $16.92 \%$ \\
\hline Push shot put by hands in front of the body & M & 10.262 & 0.113 & 12.407 & 0.486 & 14.249 & $20.90 \%$ \\
\hline push shot put by hands behind of the body & $\mathrm{m}$ & 11.280 & 0.203 & 13.898 & 0.523 & 14.085 & $23.21 \%$ \\
\hline High point of release & $\mathrm{Cm}$ & 188.100 & 1.853 & 200.400 & 3.471 & 8.554 & $6.54 \%$ \\
\hline the spead of the release & $\mathrm{m} / \mathrm{s}$ & 13.940 & 0.474 & 17.180 & 0.498 & 12.693 & $23.24 \%$ \\
\hline release angle & Degree & 26.850 & 0.709 & 31.260 & 0.438 & 16.578 & $16.42 \%$ \\
\hline throwing distance & $\mathrm{M}$ & 37.207 & 3.396 & 42.254 & 0.855 & 4.073 & $13.56 \%$ \\
\hline
\end{tabular}

T. tabular value significant at $0.05=2.101 \mathrm{D} *$

Seen from the table (4) there are significant differences between pre- and post-measurements to experimental group in the variables under study at the significant level.

Chart (2)

change rate for variables under study for the experimental group

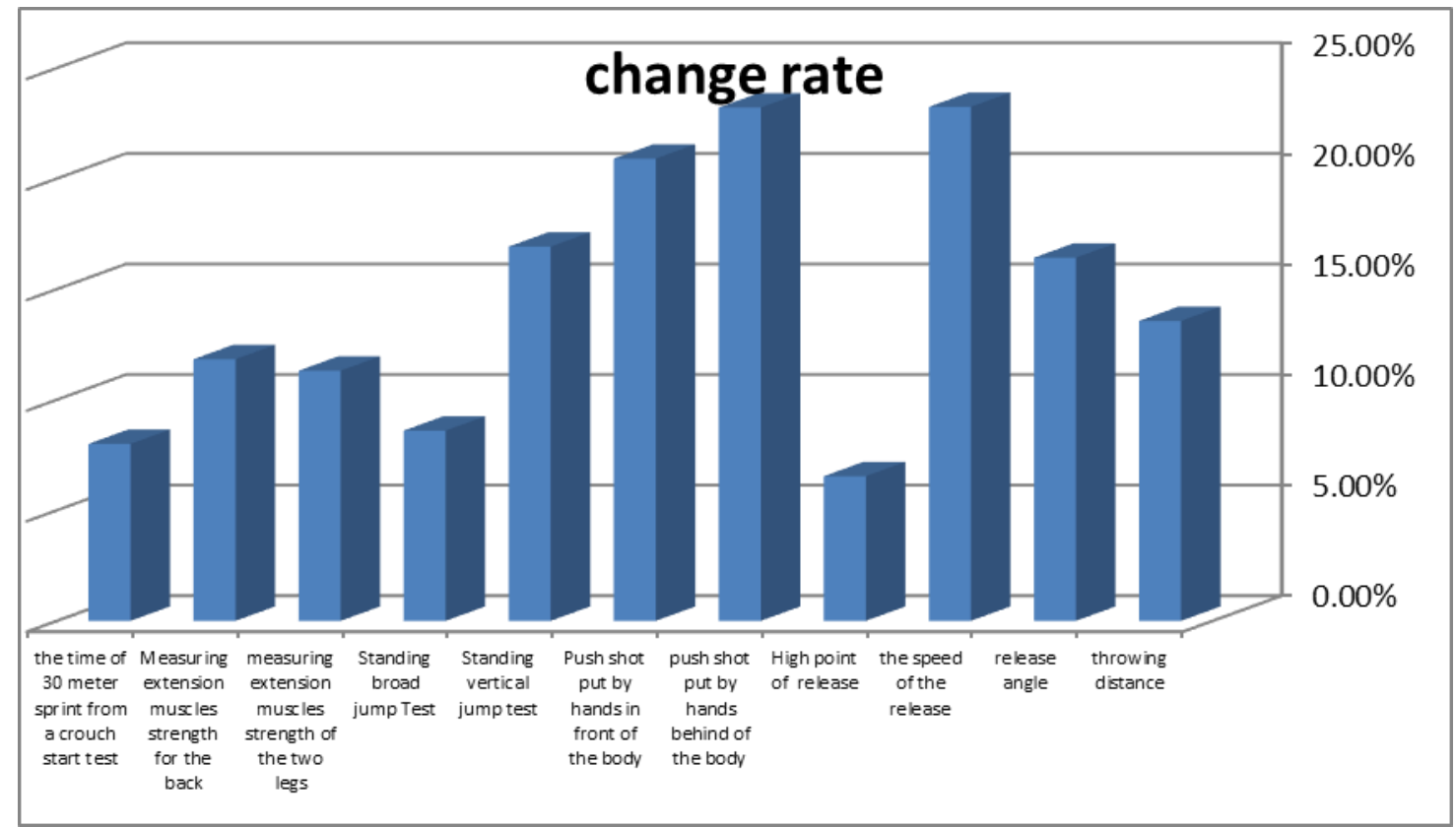

Third: the results show the differences between post measurements of the control group and the experimental of the group in the variables under study. 
Table (8)

Indication of the differences between the post tests for experimental group and post tests for the control group in variables under study

$$
\mathrm{n}=10
$$

\begin{tabular}{|c|c|c|c|c|c|c|}
\hline \multirow[b]{2}{*}{ The variables } & \multirow{2}{*}{$\begin{array}{c}\text { The unit of } \\
\text { measurement }\end{array}$} & \multicolumn{2}{|c|}{ Control group } & \multicolumn{2}{|c|}{ Experimental group } & \multirow[b]{2}{*}{$\mathrm{T}$ value } \\
\hline & & Mean & $\begin{array}{c}\text { Std. } \\
\text { Deviation }\end{array}$ & Mean & $\begin{array}{c}\text { Std. } \\
\text { Deviation }\end{array}$ & \\
\hline the time of 30 meter sprint from a crouch start test & $\mathrm{s}$ & 4.107 & 0.940 & 3.657 & 0.023 & 1.513 \\
\hline Measuring extension muscles strength for the back & $\mathrm{kg}$ & 195.110 & 4.745 & 204.090 & 6.154 & 3.654 \\
\hline measuring extension muscles strength of the two legs & $\mathrm{kg}$ & 286.100 & 4.606 & 298.100 & 6.045 & 4.993 \\
\hline Standing broad jump Test & $\mathrm{cm}$ & 238.600 & 2.413 & 245.000 & 3.944 & 4.377 \\
\hline Standing vertical jump test & $\mathrm{cm}$ & 42.600 & 1.350 & 45.600 & 1.955 & 3.993 \\
\hline Push shot put by hands in front of the body & $\mathrm{m}$ & 11.123 & 0.139 & 12.407 & 0.486 & 8.030 \\
\hline push shot put by hands behind of the body & $\mathrm{m}$ & 12.473 & 0.184 & 13.898 & 0.523 & 8.127 \\
\hline High point of release & $\mathrm{cm}$ & 195.900 & 1.853 & 200.400 & 3.471 & 3.617 \\
\hline the speed of the release & $\mathrm{m} / \mathrm{s}$ & 15.850 & 0.354 & 17.180 & 0.498 & 6.882 \\
\hline release angle & Degree & 28.250 & 0.657 & 31.260 & 0.438 & 12.057 \\
\hline throwing distance & M & 39.925 & 0.747 & 42.254 & 0.855 & 6.484 \\
\hline
\end{tabular}

T. tabular value significant at $0.05=2.101$

$\mathrm{D}^{*}$

Seen from the table (8) there are of statistically significant differences between the post measurements to experimental group and post measurements of the control group in favor of the post measurements to experimental group in the variables under study at the significant level of 0.05 , where the value of $(\mathrm{T})$ calculated higher than Tabulated value except for a variable time of $30 \mathrm{~m}$ sprint from a crouch start test.

Chart3

change rate for variables under study for the post measurements for experimental and control group

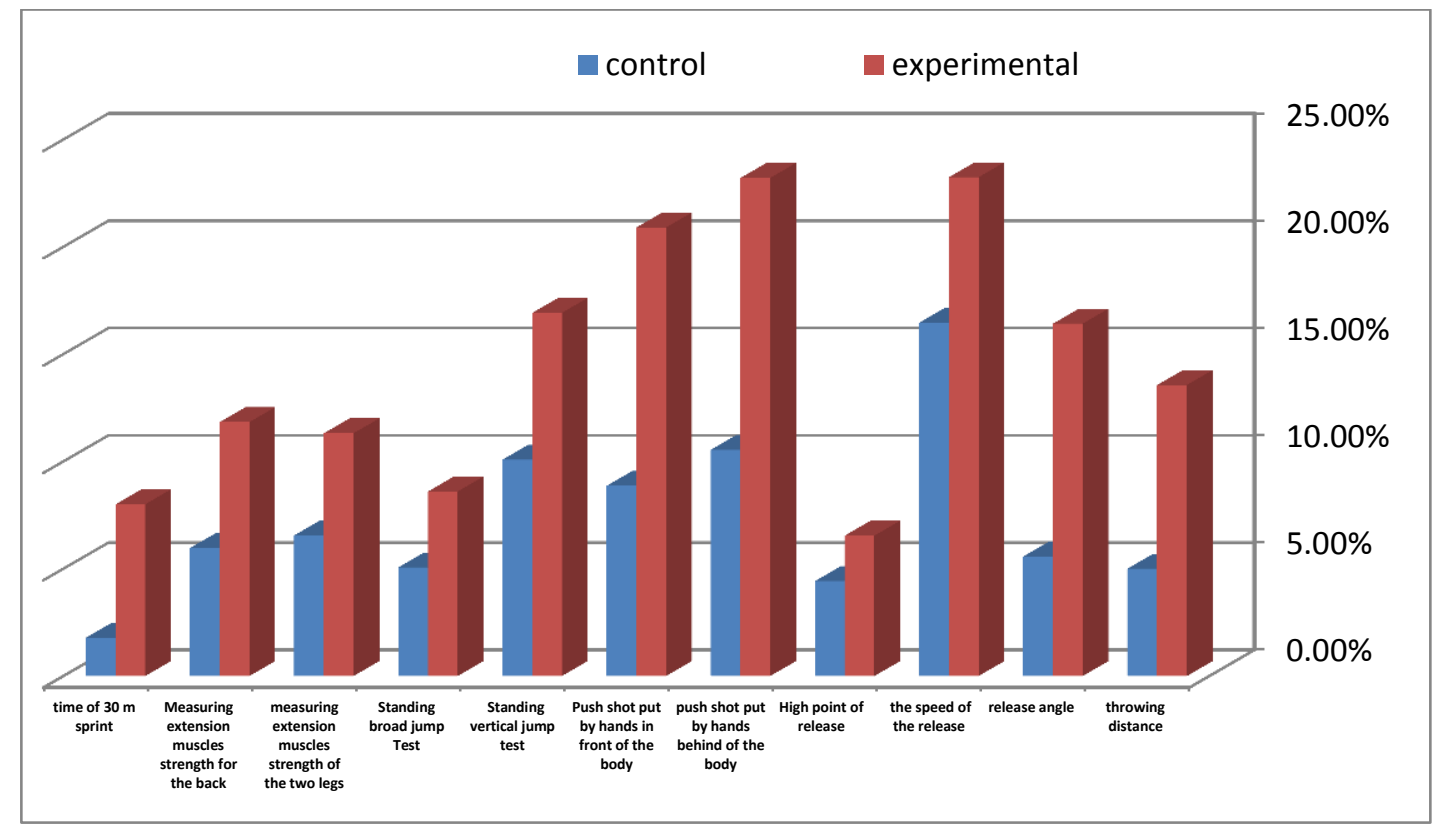

\section{Result discussions:}

Seen from the table (4) and chart (1) the presence of statistically significant differences between pre and post measurements to the control group in the variables under the study in favor of the post tests, unless the time of $30 \mathrm{~m}$ sprint from a crouch start test variable, As the values of confined to Test $(\mathrm{T})$ calculated $(0.2350,22.636)$, while the value of (T) Tabulated significant at level (0.05) (2.101). As well as confined to the percentage change between $(1.78 \%, 16.46 \%)$ had the highest percentage change in the 
spead of the release, while the lowest percentage change in the sprint $30 \mathrm{~m}$ time of crouch start. The researcher attributed these changes to the Special program control group occurs

Shown in Table5 and the chart (2) the presence of statistically significant differences between pre- tests and post tests for experimental group in the variables under study in favor of the post tests, As confined to values (T) test calculated $(4.073,14.249)$, while the value of $(\mathrm{T})$ Tabulated at the moral level (0.05) (2.101). As well as confined to the percentage change between $(8.00 \%$, $23.24 \%$ ) had the highest percentage change in the spead of the release, while the lowest percentage change in the sprint $30 \mathrm{~m}$ time of crouch start.

Due researcher these changes occur to functional strength drills program using elastic band in order to muscular strength development by training different muscle groups, especially the center muscles, arms and legs and the researcher concentrated on muscle groups working together with the accuracy choose functional strength drills where it led to improve the power.

It is evident from table 5 and the chart (3) the presence of statistically significant differences between the post tests of the control group and post measurements of experimental group in the variables under study in favor of the post measurements experimental group except for a variable time of $30 \mathrm{~m}$ sprint of the crouch start, as confined to values $(\mathrm{T})$ test calculated $(1.513,12.057)$, while the value of $(\mathrm{T})$ Tabulated at moral level (0.05) (2.101).

It is what consolation researcher of the effect of drills functional resistance using elastic band and that have been applied during Special study sample preparation on the physical variables period under study, and this is consistent with what I said Tiana Weiss et al (2010) that the functional resistance drills is one of the methods in improving fitness muscle in ways better than traditional drills including Provisions of strength training, speed and balance and coordination, as they use alternative options within the training methods compared to traditional drills as they are suitable for all ages, as well as contribute to improving all physical abilities of the athletes, as they increase and enhance the muscles strength endurance and equilibrium and agility during implementation of training programs As they lead to multiple muscles and joints of the body, during the full term of the motor joints. (11)

Due researcher percentage change in kinematic variables phase released especially throwing to the effectiveness of functional strength drills using elastic band per (10) weeks to improving speed and power for the muscles working in throw javelin competition as the duration of drills was appropriate to make working muscles adaptation. As influenced functional strength drills using elastic band in controlling body positions and acquire of the release and reach out to the mechanism stage as soon as the ideal technical performance during the release stage, which led to obtain the largest amount of power as well as a longer path to the javelin acceleration and improves their maximum spead release.

As well as increase the strength of the muscles of shoulders, chest, back and thrower arm aimed at making a positive impact on the stages of pull and push, thereby increasing the speed release the javelin and throwing distance than a positive impact on the released angle, release height, speed of release and throwing distance.

the functional training programs lead to improved neuromuscular control and integration of motor and enhance the muscle strength and power and agree with what Michel (2004) confirms that (7).

the balance is a key element in functional drills, not only the balance between strength and flexibility, but also between the muscles working and non-working and this important interactive feature in functional drills that is Confirming by Fabio Comana, (2004). (4)

And agrees the results of the current study with as indicated by the results of Khalid Waheed Ibrahim study (2013), where functional strength training drills contributed using elastic band in improving and perfecting performance through motor transport process of the lower limb to the trunk and then to the thrower arm making a positive impact on all of the release angle, the height and spead to release and throwing distance of the study.7))

\section{Conclusions:}

Through results presentation and discussion, it was possible to conclude that the Functional resistance training drills using elastic band to improve the maximum strength and power to the study sample and Functional resistance training using elastic band led to improved height and angle release spead and throwing distance of the study sample in the javelin event.

\section{Recommendations:}

In light of research conclusion researcher recommends that Functional resistance training drills using elastic band to improve the maximum strength and power to the study sample, Functional resistance training using elastic band led to improved height and angle release speed and throwing distance of the study sample in the javelin event. The use of functional resistance drills using elastic band within training programs for all throwing competitions. variety in the application of functional drills using elastic resistance band muscles party the upper and lower muscles of the center (core muscles) because of its positive effect on the technical performance. The need for strength 
measurements muscles party the upper and lower muscles and stability the center (core muscles) and equilibrium and motor kinetic analysis and work to improve them during different training periods.

\section{References:}

1. Chiu, C (2009): Discovering Optimal Release Conditions for the Javelin World Record Holders by Using Computer Simulation, International Journal of Sport and Exercise Science.Pp13

2. Christine Cunningham (2000): The Importance of Functional Strength Training, Personal Fitness Professional magazine, American Council on Exercise publication, April.Pp3,33

3. Dave Schmitz (2003): Functional Training Pyramids, New Truer High School, Kinetic Wellness Department, USA.Pp3

4. Essam El-Din Shaaban on, Ody Gaspe Hassan (2009): Evaluation kinematic variables world champion Jan Zalzeny in the javelin throw, Scientific International Sports Conference sixth sport and development, look toward the third millennium, Faculty of Physical Education, University of Jordan. pp378.

5. Essam El-Din Shaaban on, Ody Gaspe Hassan2010: variables semifinalists elite in the javelin as a function of industry Olympic champion, Journal of Sports Sciences to assess the first issue, the University of Diyala, Iraq. P 381.

6. Fabio comana (2004): function training for sports, Human Kinetics: Champaign IL, England.Pp87

7. Firas Mohammed Hussein (2002): Theffect of the use of a proposed at the level of performance of the two phases of the transmission and disposal in the javelin competition for beginners, master's study unpublished, Faculty of Physical Education for Boys, Abu Qir, Alexandria University. Pp. 49.

8. Hana Rashwan Abdullah (2013): kinematic variables to throw the javelin as a basis for exercises to improve the quality of the digital level for juniors, master's study unpublished, Faculty of Physical Education, University Almnia.pp 29.

9. Hikmat Abdul Karim Salman

, Maher Abdallah Salman (2009): A study of some Elkinmetekih variablesand their relationship to the level of achievementthrew the javelin with students of the Faculty of Physical Education, University of Maysan, Volume9th Issue 3th, Qadisiyah journal of Science of Physical Education, University of Maysan, Iraq. Pp3.

10. Khaled Wahed Ebrahim (2013): The effect of the use of the javelin commentator on some variables
Kinematics stage disposed in the javelin competition, published research, the scientific journal Science Physical Education and Sports, Issue 10th, Faculty of Physical Education, Mansoura University.Pp1

11. Khaled Waheed Ibrahem (2014) : Effect of functional resistance Drills with Elastic bands on performance of Release Phase in Shot Put Competition. Theories\&Applications, the International Edition of the Official , peer-Reviewed Journal of the faculty of physical Education for boys,Alexandria Univeristy,under published.pp7.

12. Maryniak, J, Kozdraś, E, Golińska, E (2009): Mathematical Modeling and Numerical Simulations of Javelin Throw, Human Movement, Vol.10 (1).Pp1920

13. Michael Boyle (2004): Functional Balance Training Using a Domed Device ,j Spine, 21, pp2640-2650 .

14. Mohamed Jaber Brekaa, Kharya Elsokary(2002): The basic principles of bio-mechanics in the field of sports, Knowledge Institution, Alexandria.Pp29

15. Murakami,m et al (2006) : Biomechanical analysis of the javelin throwing at 11th IAAF World Championships in Athletics in Helsinki, new studies athletics,no ( 2 ) .Pp67

16. Scott Gaines (2003): Benefits and Limitations of Functional Exercise, Vertex Fitness , NESTA , USA.Pp214

17. Tiana Weiss, Jerica Kreitinger, Hilary Wilde, Chris Wiora, Michelle Steege Lance Dalleck, Jeffrey Janot, (2010) : Effect of Functional Resistance Training on Muscular Fitness Outcomes in Young Adults, J Exerc Sci Fit . Vol 8. No 2 .pp 113-122

18. tom, P (2001): Basic Technique in the Javelin throw, track Coaches.Pp6.

19. Viitasalo,J,Mononen,H,Norvapalo,K (2003) : Release Parameters at The Foul Line and The Official Result in Javelin Throwing, Sports Biomechanics, Vol.( 2 )Pp16.

20. Wallace, BJ, Winchester, JB, and McGuigan, MR (2006): Effects of elastic bands on force and power characteristics during the back squat drills. Journal of Strength Condition Resistance, 20: pp. 268-272. 
